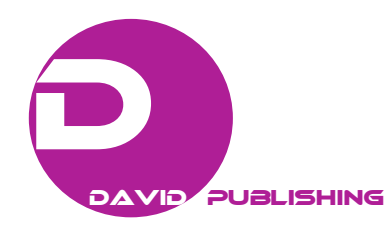

\title{
Comparison of Traffic Growth Factors in Three Major Highways of Bangladesh: A Case Study
}

\author{
Mohammad Ahad Ullah ${ }^{1}$, Hamid Nikraz ${ }^{1}$ and Md. Shamsul Hoque ${ }^{2}$ \\ 1. Department of Civil Engineering, Curtin University, Perth 6102, Australia \\ 2. Department of Civil Engineering, BUET (Bangladesh University of Engineering and Technology), Dhaka 1000, Bangladesh
}

\begin{abstract}
The unanticipated increase in vehicle population and heavy axle loads has brought the road network of Bangladesh to a crumbling stage. The network is grossly short of its structural capacity, highly distressed and has started showing signs of premature failure. The RHD (Roads and Highways Department) of Bangladesh uses $8 \% \sim 10 \%$ growth rate of traffic for structural design of these highways that need to be upgraded due to present high traffic volume demand. An attempt has been made through this case study, by using traffic flow data from different computerized toll plaza established in recent times, to predict traffic growth pattern of different highways of Bangladesh. The toll collectors of different computerized toll plaza have been recording and preserving round-the-year continuous flow data in a systematic manner. The study has taken this prospect of utilizing several years of flow data along Dhaka-Chittagong Highway (N-1), Dhaka-Sylhet Highway (N-2), Dhaka-North Bengal Highway (N-5) and found the traffic growth factor of $21.03 \%, 23.79 \%$ and $11.31 \%$, respectively, which is much higher than that transport authority of Bangladesh is currently using. By the use of accurate traffic engineering parameters such as traffic growth factors, it is possible to resist frequent distress of pavement and sustainable pavement management can be implemented by RHD.
\end{abstract}

Key words: Traffic growth factor, traffic volume, national highway, geometric design standard.

\section{Introduction}

The study of vehicular flow characteristics is very helpful for developing highway and transportation plans, performing economic analyses, evaluating the performance of transportation facilities and establishing geometric criteria. Increase of growth rate of traffic is a normal incident in developing countries like Bangladesh. Substantial agricultural and economic growth in different sectors during the last 20 years caused considerable increase in passenger and freight movement for the whole country. From the transportation point of view, it is of great importance to investigate the pattern of actual traffic growth trends in all major highway locations in a country. Growth factor of traffic is a vital parameter for prediction of future traffic demand and therefore carries significant importance in terms of planning,

Corresponding author: Mohammad Ahad Ullah, Ph.D. candidate, research field: civil engineering. E-mail: m.ullah2@postgrad.curtin.edu.au. designing of new highway facilities, as well as operation and maintenance of existing facilities, toll collection and other related issues.

For the analyses of traffic growth pattern, long duration continuous traffic flow data along a specific location of highway are required [1-3]. Hence for this case study, traffic data have been collected continuously for a long period along the selected corridors and presented for a number of consecutive days, weeks, months, years etc., then the repetitive nature of the variations has been observed, since the pattern of the daily, weekly, monthly variations is similar for all years, although the actual volumes may not necessary be the same. If there is any external factor, which may influence flow pattern, the cyclic property of yearly flow will not be observed distinctively. As such, before the analysis of vehicular flow, all unusual data will be eliminated from the database to ensure natural periodic variation of traffic stream flow. To achieve this objective, efforts are 
made to prepare an event calendar by gathering information related to hartal, transport strike, natural calamity, like flood, etc., which are very unpredictable in nature and have the potential to affect the normal pattern of traffic flow. In this regard, officials of various tolls collecting agency and Meteorological Department of Bangladesh are contacted and daily newspapers are consulted.

The raw database is then formatted in line with the objectives of the case study and requirement of statistical software. The features that are analyzed including the determination of vehicular flow, composition, directional distribution, peak hour volume, design hour volume, vehicle wise growth rate, percentage of trucks, flow fluctuations with respect to daily, weekly, monthly, seasonally, yearly, etc.. Considering the economic status of Bangladesh, it is quite understandable that this is an expensive task for the government to take the initiative to set up permanent traffic counting stations at important locations, since the measure requires high fixed and running cost. As a result, the highway authority has never been able to record and preserve the continuous traffic flow data by which an authentic traffic growth pattern or rate could be analyzed. For example, Roads and Highways Pavement Design Guide 2005 sets $8 \% \sim 10 \%$ growth rate for the national highways of Bangladesh that become obsolete now in terms of present traffic flow [4]. However, the compatibility of this value with the actual growth rate can only be compared, if true growth rate analyses can be made on the basis of actual continuous traffic flow data.

\section{Objectives and Scope of the Study}

The main objective of this study is to analyze yearly traffic growth factor of three major highways of Bangladesh based on daily traffic flow data and compare those with geometric design standard of RHD (Roads and Highways Department) of Bangladesh.

This study has been performed on: (1)
Meghna-Gomoti Bridges traffic data along Dhaka-Chittagong Highway (N-1) which is the busiest road and the main transportation artery in Bangladesh; (2) Bhairab-Ashuganj Bridges traffic data along Dhaka-Sylhet Highway (N-2) that links the country's capital Dhaka and the town of Tamabil in Sylhet district; (3) Jamuna Bridge traffic data along Dhaka-North Bengal Highway (N-5) of Bangladesh that connects the capital Dhaka and the town of Banglabandha on the Bangladesh-India border. These corridor selections have been mainly governed by the availability of sufficient amount of high quality traffic data.

\section{Literature Review}

Study on traffic flow pattern and its variability over time carries a great importance to understand the characteristics of a traffic stream. Analyses of traffic flow pattern from existing data are performed to determine important characteristics of traffic flow that are used in geometric and structural design of highways, traffic monitoring programs, roadway maintenance and operation, economic evaluation, traffic flow prediction, highway financing, evaluation of safety programs and many other related decision making.

While transport authorities and agencies in many developed countries extensively record traffic flow data through short counting as well as continuous counting stations in order to monitor their trend of traffic growth and changes in traffic characteristics, not many studies have been performed in Bangladesh on traffic characteristics. Previously performed studies in Bangladesh on related topic revealed that similar studies were carried out by Roads and Highways Department, as a part of Development of Geometric Design Standards in 1994, on some important highways [3]. Another similar work was carried out by Road and Railway Division in 1996, Government of Bangladesh [5].

Rahman [6] performed studies on vehicular flow 
pattern on Jamuna multipurpose bridge access road in 2002. Zaman [7] completed another study in "Traffic Flow Characteristics and Modeling for Estimation of AADT (Annual Average Daily Traffic) in Selected Rural Highways" in 2006. Ullah [8] carried out research on "Evaluation of Pavement Design Parameters for National Highways of Bangladesh". In addition, guidelines are followed for analysis of traffic characteristics from "Traffic Monitoring Guidelines" in 2011, published by Federal Highway Administration of US Department of Transport, which have been helpful for this type of case study [9].

\section{Data Collection}

The traffic data that have been used in this study for the growth pattern analyses are primarily collected from three major toll operation companies of Bangladesh. For Dhaka-Chittagong Highway (N-1), data have been collected from the operation and maintenance companies, called RCL (Reza Construction Limited) and MBEL (Mohiuddin Builders and Engineers Limited)-ATT (Asian Traffic Technologies Limited JV (joint venture)), of Meghna-Gomoti Bridges from the year 2006 to 2009. In the same way, from the year 2007 to 2009 , traffic data have been collected from RCL, the toll operation and maintenance companies of Bhairab-Ashuganj Bridges along Dhaka-Sylhet Highway (N-2). In addition, for Dhaka-North Bengal Highway (N-5), data have been collected from the largest bridge of Bangladesh called Jamuna Bridge where the toll operators were MNOL (Marga Net One Limited) and BBSO (Bangabandhu Bridge Special Organization).

The traffic data have been recorded by the operators by direct entry from the toll plaza and they have been electronically preserved in the main database. These flow data have then been collected from the operators with official permission from RHD of Bangladesh and have been used in this study for performing the required analyses. From the analyses of flow pattern in different time scales, the data have resulted in repetitive nature of flow patterns, which refers that the selected corridors are stable from traffic flow point of view and the traffic data are reliable.

\section{Data Analyses and Findings}

In this study, growth pattern of total traffic in three major highways has been analyzed. Yearly growth factors of total traffic have been determined. The following section discusses the traffic growth trend and rates in light of the data analysis.

\subsection{Growth Rate of Total Traffic on Dhaka-Chittagong Highway (N-1)}

From the analyses of yearly traffic volume in Dhaka-Chittagong Highway on Meghna-Gomoti Bridges, it has been revealed that the amount of traffic is increasing at a higher rate. In 2006, the total bi-directional traffic volume was 3,206,277 while it reached almost 5.6 million in the year 2009. Table 1 shows the bi-directional flow volume of each vehicle class as well as total traffic on Meghna-Gomoti Bridges from 2006 to 2009. From Fig. 1, it can be seen that the total traffic is increasing every year at a significant rate and the pattern maintains almost linear growth of traffic. From the calculation of yearly growth rate, as shown in Table 2, it is found that, yearly increase in traffic during the study period has

Table 1 Yearly bi-directional traffic volume on Dhaka-Chittagong Highway (N-1).

\begin{tabular}{lrrrr}
\hline \multirow{2}{*}{ Vehicle class } & \multicolumn{4}{c}{ Yearly bi-directional traffic volume } \\
\cline { 2 - 5 } & \multicolumn{1}{c}{2006} & \multicolumn{1}{c}{2007} & \multicolumn{1}{c}{2008} & \multicolumn{1}{c}{2009} \\
\hline Motor cycle & 9,743 & 22,729 & 36,975 & 46,896 \\
Scooter/tampo & 15,976 & 76,496 & 206,866 & 291,080 \\
Car/jeep & 433,710 & 569,262 & 609,759 & 756,199 \\
Micro/pickup & 455,243 & 667,038 & 742,149 & 994,568 \\
Minibus/coaster & 431,617 & 570,851 & 524,010 & 535,970 \\
Bus & 500,227 & 680,413 & 715,618 & 788,149 \\
Truck & $1,178,966$ & $1,459,489$ & $1,594,506$ & $1,876,198$ \\
Trailer & 47,118 & 89,800 & 101,870 & 115,995 \\
Toll free vehicle & 133,677 & 177,759 & 201,196 & 227,743 \\
\hline Total & $3,206,277$ & $4,313,837$ & $4,732,949$ & $5,632,798$ \\
\hline
\end{tabular}




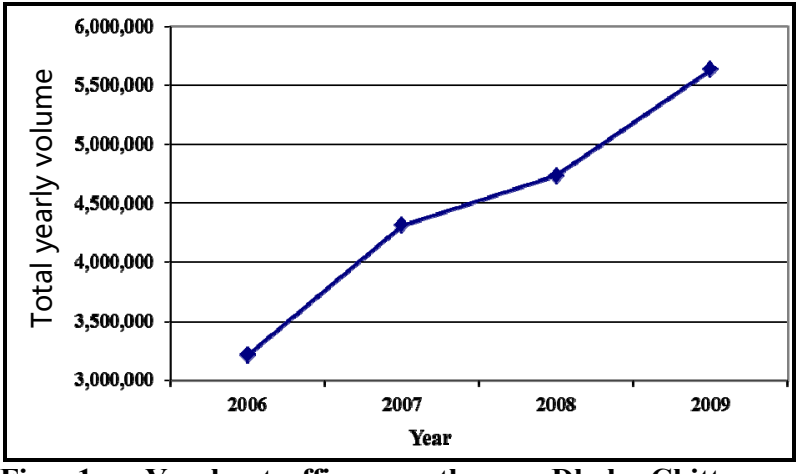

Fig. 1 Yearly traffic growth on Dhaka-Chittagong Highway (N-1).

Table 2 Yearly growth rate of total traffic on N-1.

\begin{tabular}{llll}
\hline Year & $\begin{array}{l}\text { Total yearly volume } \\
\text { (both way) }\end{array}$ & $\begin{array}{l}\text { Growth factor } \\
(\%)\end{array}$ & $\begin{array}{l}\text { Average growth } \\
\text { factor }\end{array}$ \\
\hline 2006 & $3,206,277$ & - & \\
2007 & $4,313,837$ & 34.370 & $21.03 \%$ \\
2008 & $4,732,949$ & 9.716 & \\
2009 & $5,632,798$ & 19.012 & \\
\hline
\end{tabular}

ranged from $9.7 \%$ to $34.37 \%$ per annum and the average growth factor of total traffic from 2006 to 2009 is $21.03 \%$ per annum.

It can be observed in Table 2 that the growth rate of total traffic in 2007 was $34.37 \%$, which is much higher than the following years. Therefore, it can be concluded that the traffic growth trend along this corridor is not yet stable. What needs to be mentioned here is that economic growth is not the only governing issue against this growth pattern, but also political stability, government policy, availability of alternate route and shifting of traffic to the study corridor play important roles in this regard.

5.2 Growth Rate of Total Traffic on Dhaka-Sylhet Highway (N-2)

Investigation of daily traffic volume in Bhairab-Ashuganj Bridges along Dhaka-Sylhet Highway discloses that traffic along this corridor is not stable yet and needs detail investigation of more years of long-term daily traffic data. Table 3 shows the bi-directional flow volume of each vehicle class as well as total traffic on Dhaka-Sylhet Highway from the year 2007 to 2009 . It is seen from the table that individual vehicle class of traffic along this corridor is increasing at a higher rate.

In addition, from the data of Table 4, a graph is plotted in Fig. 2 where the total bi-directional yearly traffic volume on Dhaka-Sylhet Highway (N-2) corridor is shown against respective years from 2007 to 2009. In 2007, the total yearly traffic volume was $1,448,549$. During the next year, it has drastically increased and become 2,164,444 in 2008. The growth rate has been found to be $49.42 \%$, which is much higher than average national growth rate $(8 \% \sim 10 \%)$ used in the roads and highways design manual. But in 2009, the traffic volume decreased to $2,124,540$ and so the growth factor becomes $-1.84 \%$, which is very surprising with respect to Bangladesh condition. However, the average growth rate has been found to be $23.79 \%$ per annum in $\mathrm{N}-2$ corridor.

Table 3 Yearly bi-directional traffic volume on Dhaka-Sylhet Highway (N-2).

\begin{tabular}{|c|c|c|c|}
\hline \multirow{2}{*}{ Vehicle class } & \multicolumn{3}{|c|}{ Yearly bi-directional traffic volume } \\
\hline & 2007 & 2008 & 2009 \\
\hline Motor cycle/baby texi/mishuk & 251,433 & 412,924 & 517,380 \\
\hline Maxi/pick-up van/pick-up/tampo & 84,337 & 292,489 & 139,455 \\
\hline Car/jeep/station wagon/micro & 296,928 & 486,878 & 504,380 \\
\hline Coaster/tractor/tractor with trailer & 6,633 & 7,514 & 9,262 \\
\hline Minibus/minitruck & 57,584 & 67,012 & 78,266 \\
\hline Bus/truck/covered truck 2 axle & 708,531 & 848,230 & 834,520 \\
\hline Bus/truck/covered truck 3 axle & 12,665 & 15,346 & 18,031 \\
\hline Trailer truck/construction equipment & 2,327 & 6,257 & 1,471 \\
\hline Toll free vehicle & 28,111 & 27,794 & 21,775 \\
\hline Total traffic & $1,448,549$ & $2,164,444$ & $2,124,540$ \\
\hline
\end{tabular}


Table 4 Yearly growth rate of total traffic in N-2.

\begin{tabular}{llll}
\hline Year & $\begin{array}{l}\text { Total yearly volume } \\
\text { (both way) }\end{array}$ & $\begin{array}{l}\text { Growth } \\
\text { factor (\%) }\end{array}$ & $\begin{array}{l}\text { Average growth } \\
\text { factor }\end{array}$ \\
\hline 2007 & $1,448,549$ & - & \\
2008 & $2,164,444$ & 49.42 & $23.79 \%$ \\
2009 & $2,124,540$ & -1.84 & \\
\hline
\end{tabular}

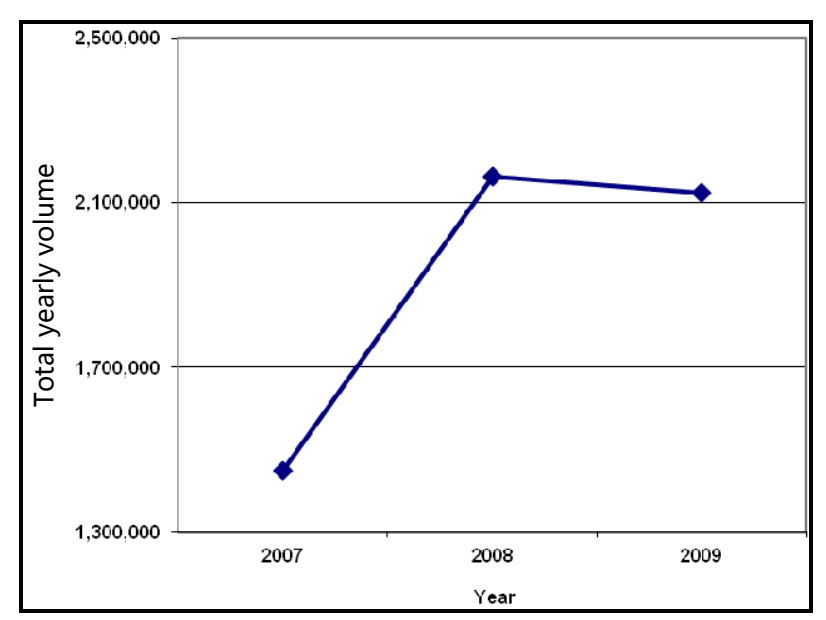

Fig. 2 Yearly traffic growth on Dhaka-Sylhet Highway (N-2).

\subsection{Growth Rate of Total Traffic in Dhaka-North Bengal Corridor (N-5)}

It is found that, from flow pattern analyses of Jamuna Bridge corridor, although the daily, weekly and monthly flow variation exhibits similar fluctuation pattern, but the magnitude of flow increases every successive year. This indicates that since the stabilization of the corridor, total yearly traffic is gradually increasing. An analysis of traffic growth pattern is important for reliable prediction of future traffic flow by extrapolation method. Moreover, for estimating future traffic for geometric and structural design or prediction of future traffic flow in terms of PCU (passenger car unit) and total ESAL (equivalent single axle load), the pattern of growth rate of traffic is necessary. Tables 5 and 6 show the bi-directional flow volume of each vehicle class along with total traffic on Jamuna Bridge from 2005 to 2009 to understand the true pattern of traffic growth.

In addtion, Fig. 3 plots the total bi-directional yearly traffic volume on Jamuna Bridge against respective years from 2005 to 2009 . From the graph, it is clearly seen that yearly traffic growth is almost linear. In 2005, the total yearly traffic volume was $1,930,313$. During the next 4 years, it has gradually increased and has become near about 3 million (exact figure is 2,962,192) in 2009. The average growth rate has been found to be $11.31 \%$ per annum, which is higher than average national growth rate $(8 \% \sim 10 \%)$ used in the roads and highways design manual [4].

\section{Conclusions and Recommendations}

Accurate estimation of traffic growth factor is essential for proper road and traffic management system. Currently, Roads and Highways Department of Bangladesh uses vehicular growth factor of $8 \% \sim 10 \%$ per annum that was established in 2005. Recent severe recurrent damages of major highways are a big concern of Government of Bangladesh. As the roads of Bangladesh are designed for $8 \% \sim 10 \%$ traffic growth factor, but in this study, it is found that the actual growth factor of major highways is much higher than

Table 5 Yearly bi-directional traffic volume on Dhaka-North Bengal Highway (N-5).

\begin{tabular}{|c|c|c|c|c|c|}
\hline \multirow{2}{*}{ Vehicle class } & \multicolumn{5}{|c|}{ Yearly bi-directional traffic volume } \\
\hline & 2005 & 2006 & 2007 & 2008 & 2009 \\
\hline Large bus & 632,938 & 683,070 & 754,136 & 803,648 & 855,390 \\
\hline Medium truck & 771,500 & 804,071 & 905,213 & 959,467 & $1,042,748$ \\
\hline Light vehicle & 289,910 & 325,570 & 367,540 & 442,241 & 543,832 \\
\hline Small bus & 30,720 & 27,376 & 25,362 & 23,892 & 16,025 \\
\hline Small truck & 134,709 & 164,791 & 243,766 & 347,774 & 423,137 \\
\hline Motor cycle & 42,155 & 48,078 & 36,380 & 47,117 & 60,012 \\
\hline Large truck & 28,381 & 27,538 & 18,412 & 16,622 & 21,048 \\
\hline Total vehicles & $1,930,313$ & $2,080,494$ & $2,350,809$ & $2,640,761$ & $2,962,192$ \\
\hline
\end{tabular}


Table 6 Yearly growth rate of total traffic.

\begin{tabular}{llll}
\hline Year & $\begin{array}{l}\text { Total yearly volume } \\
\text { (both way) }\end{array}$ & $\begin{array}{l}\text { Growth factor } \\
(\%)\end{array}$ & $\begin{array}{l}\text { Average growth } \\
\text { factor }\end{array}$ \\
\hline 2005 & $1,930,313$ & - & \\
2006 & $2,080,494$ & 7.78 & \\
2007 & $2,350,809$ & 12.99 & $11.31 \%$ \\
2008 & $2,640,761$ & 12.33 & \\
2009 & $2,962,192$ & 12.17 & \\
\hline
\end{tabular}

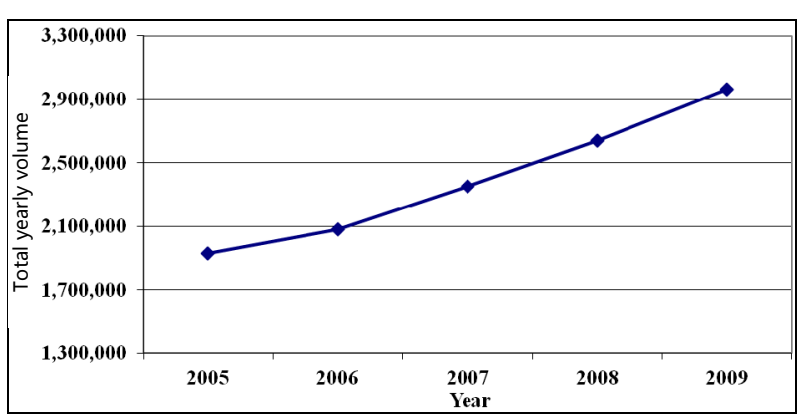

Fig. 3 Yearly traffic growth on Dhaka-North Bengal Highway (N-5).

anticipated. Developing countries like Bangladesh has densely populated human resource and recent economic enhancement in every sector formulates massive amount of traffic movement along the highways. Major highways are required to be upgraded based on current traffic load assessment in order to build road less vulnerable to traffic. Without fast and efficient transportation system, development of economic expansion is not possible. An attempt was made through this study to compare the recent growth factor of traffic along major highways of Bangladesh. Though passenger car and freight car have a different impact on traffic volume, as a preliminary research, different kinds of vehicles have been aggregated to calculate total volume of each corridor in Bangladesh. Nevertheless, 4 or 5 years of data are not sufficient to reliably analyze the actual growth pattern of traffic in major highways in Bangladesh. This case study has taken an attempt because presently no further continuous count data are available along those corridors. From the analyses performed in this study, generalized ideas of traffic growth trend in the selected corridors have been discovered.

By the way, the following recommendations are suggested which would be largely beneficial for future prediction of traffic growth patterns in major highways of Bangladesh:

- RHD of Bangladesh should carry a large scale traffic flow survey periodically along major highways of Bangladesh in order to correctly measure traffic demand;

- On the other hand, a specified data collection and preservation system in electronic format can be introduced by RHD to ensure proper data collection in tolled bridges without spending any money for data collection purpose;

- For all national highways of Bangladesh, growth factor of the vehicle is considered $8 \% \sim 10 \%$ per year. But in this research, average growth rate of total traffic in N-1, N-2 and N-5 corridors is found to be accordingly $21.03 \%, \quad 23.79 \%$ and $11.17 \%$, respectively. Therefore, up gradation of growth factor parameter is necessary for all highways in Bangladesh. It is also to be mentioned that flat growth rate of total vehicle is not representative of all vehicles class and growth rate of individual vehicle class may be considered for more accuracy. Corridor specific traffic growth factor should be established which will help to measure future traffic demand properly;

- Class wise vehicular growth factors should be considered and the same should be regularly updated using recently data;

- Initiative may be taken to instruct all highway toll operators to keep flow records in hourly basis. A valuable traffic database can be generated in every corridor by introducing this technique.

\section{References}

[1] Sharma, S. C. 1989. "Prediction of Design Hourly Volume from Road Users Perspective." Transportation Engineering 115 (5): 646-60.

[2] Kaub, A. R. 1988. "Design Guide for Auxillary Passing Lanes on Rural Two-Lane Highways." Transportation Research Record 1195: 92-100.

[3] Development of Geometric Design Standards. 1994. Road Material and Standards Study Bangladesh. Roads and Highways Department, Government of Bangladesh. 
[4] Roads and Highways Department. 2005. Pavement Design Guide. Ministry of Communication, Government of Bangladesh.

[5] Road and Railway Division. 1996. Country Paper on Bangladesh Road and Road Transport. Ministry of Communication, Government of Bangladesh.

[6] Rahman, S. K. 2002. "Study of Vehicular Flow Pattern on Jamuna Multipurpose Bridge Access Road.” M.Sc. thesis, MIST (Military Institute of Science and Technology).
[7] Zaman, H. U. 2006. "Traffic Flow Characteristics and Modeling for Estimation of AADT in Selected Rural Highways.” M.Engg. thesis, BUET (Bangladesh University of Engineering and Technology).

[8] Ullah, M. A. 2012. "Evaluation of Pavement Design Parameters for National Highways of Bangladesh.” M.Sc. thesis, BUET.

[9] Federal Highway Administration. 2011. Traffic Monitoring Guidelines. US Department of Transport. 